2-25-2003

\title{
Measurement of the Anti-Cancer Agent Gemcitabine in Human Plasma by High-Performance Liquid Chromatography
}

\author{
Bruce Keith \\ National Cancer Institute at the National Naval Medical Center \\ Yan Xu \\ Cleveland State University, y.xu@csuohio.edu \\ Jean L. Grem \\ National Cancer Institute at the National Naval Medical Center
}

Follow this and additional works at: https://engagedscholarship.csuohio.edu/scichem_facpub

Part of the Analytical Chemistry Commons

How does access to this work benefit you? Let us know!

\section{Recommended Citation}

Keith, Bruce; Xu, Yan; and Grem, Jean L., "Measurement of the Anti-Cancer Agent Gemcitabine in Human Plasma by High-Performance Liquid Chromatography" (2003). Chemistry Faculty Publications. 201. https://engagedscholarship.csuohio.edu/scichem_facpub/201

This Article is brought to you for free and open access by the Chemistry Department at EngagedScholarship@CSU. It has been accepted for inclusion in Chemistry Faculty Publications by an authorized administrator of EngagedScholarship@CSU. For more information, please contact library.es@csuohio.edu. 


\title{
Measurement of the anti-cancer agent gemcitabine in human plasma by high-performance liquid chromatography
}

\author{
Bruce Keith, Yan Xu, Jean L. Grem
}

\section{Introduction}

Gemcitabine $\left(2^{\prime}-2^{\prime}\right.$-difluorodeoxycytidine, dFdC) is a deoxycytidine analog in which the deoxyribose moiety contains two fluorine atoms in place of hydrogen at the $2^{\prime}$-position (Fig. 1). Its anti-neoplastic activity is mediated though inhibition of DNA

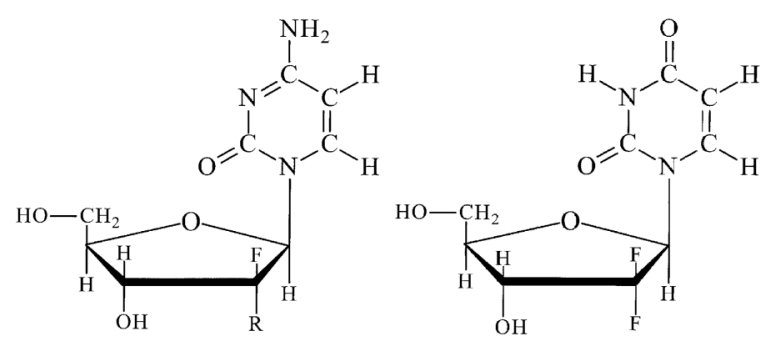

Fig. 1. The chemical structures $\mathrm{dFdC}(\mathrm{R}=\mathrm{F}), \mathrm{FdC}(\mathrm{R}=\mathrm{H})$, and dFdU. 
synthesis [1-3]. The diphosphate derivative inhibits ribonucleotide reductase, thereby depleting the endogenous deoxyribonucleotide triphosphate pools. The triphosphate derivative is incorporated into DNA and subsequently interferes with DNA chain elongation. Gemcitabine is deaminated to the inactive metabolite $2^{\prime}, 2^{\prime}$-difluorodeoxyuridine ( $\mathrm{dFdU}$ ) by cytidine deaminase. Gemcitabine is used clinically to treat a variety of solid tumors, particularly pancreatic, bladder and non-small cell lung cancers.

Preclinical studies conducted in our laboratory suggested that the combination of $\mathrm{dFdC}$ for $4 \mathrm{~h}$ followed by a 24 -h exposure to 5-fluoro- $2^{\prime}$-deoxyuridine (FdU) resulted in more than additive cytotoxicity and enhanced DNA damage in a human colon cancer cell line [4]. Therefore, a Phase I trial of weekly $\mathrm{dFdC}$ followed by a 24-h infusion of FdU was designed. To permit determination of the plasma levels of $\mathrm{dFdC}$ and $\mathrm{dFdU}$ in patient samples, a reversed-phase HPLC assay was developed.

\section{Experimental conditions}

\section{Chemicals}

The commercial formulation of gemcitabine hydrochloride (each vial contains $200 \mathrm{mg}$ of gemcitabine as the free base, $262.9 \mathrm{~g} / \mathrm{mol}$ ) was purchased from Eli Lilly and Company (Indianapolis, IN, USA). dFdU was generously provided by Lilly Research Laboratories though a material transfer agreement with the National Cancer Institute (NCI). FdC (HPLC internal standard), was purchased from Sigma (St Louis, MO, USA). Tetrahydrouridine (THU), an inhibitor of cytidine deaminase, was provided by the Drug Synthesis and Chemistry Branch, Developmental Therapeutics Program, Division of Cancer Treatment and Diagnosis, NCI, National Institutes of Health (NIH), Bethesda, MD, USA [5]. Glacial acetic acid (analytic reagent (AR) grade) and sodium acetate (AR grade) were from Mallinckrodt (Paris, KY, USA). HPLC grade water, methanol and acetonitrile were from Fisher (Fair Lawn, NJ, USA). All other chemicals were AR grade. Pooled donor plasma was obtained from the Department of Transfusion Medicine, Warren G.
Magnusen Clinical Center, NIH (Bethesda, MD, USA).

\section{Standard solutions}

Stock solutions of $\mathrm{dFdC}, \mathrm{dFdU}$ and $\mathrm{FdC}$ at concentrations of $10 \mathrm{~m} M(2.63 \mathrm{mg} / \mathrm{ml}), 7.57 \mathrm{~m} M(2$ $\mathrm{mg} / \mathrm{ml})$ and $10 \mathrm{mM}(2.44 \mathrm{mg} / \mathrm{ml})$, respectively, were prepared in water; aliquots were stored at $-30{ }^{\circ} \mathrm{C}$. Calibration standards were prepared by appropriate dilutions of the $\mathrm{dFdC}$ stock solutions with water to generate $10 \times$ calibration standards at concentrations ranging between 5 and $1500 \mu M$; aliquots were stored at $-30{ }^{\circ} \mathrm{C}$; dilutions of the $\mathrm{dFdU}$ stock solutions with water generated $10 \times$ calibration standards ranging from 5 to $2270 \mu M$. Plasma calibration standards were made by adding $50 \mu \mathrm{l}$ of a $10 \times$ calibration standard solution to 0.5 $\mathrm{ml}$ of plasma to give final concentrations upon reconstitution of the extracted plasma sample that ranged between 0.5 and $150 \mu M$ for $\mathrm{dFdC}$ or 0.5 and $227 \mu M$ for dFdU. Fifty microliters of $250 \mu M$ FdC or $20 \mu \mathrm{l}$ of $1 \mathrm{~m} M \mathrm{FdC}$ was added to $0.5 \mathrm{ml}$ plasma to give a final concentration of 25 or $40 \mu M$ (see Section 3.1).

\section{Sample preparation}

Standard curves were prepared in pooled plasma which was placed on ice immediately upon thawing. Aliquots of $0.5-\mathrm{ml}$ test plasma were placed in $12 \times 75$ $\mathrm{mm}$ glass tubes on ice; calibration standards and 20 $\mu \mathrm{l}$ of $1 \mathrm{~m} M$ internal standard were added. Glacial acetic acid $(50 \mu \mathrm{l})$ was added to decrease hydrogen bonding between the nucleosides and proteins. After the addition of $1 \mathrm{ml}$ of acetonitrile, the samples were vortex-mixed. Following centrifugation at $800 \mathrm{~g}$ for $15 \mathrm{~min}$ at $4{ }^{\circ} \mathrm{C}$, the supernatant was removed. To improve the recovery (see Section 3.2), $1 \mathrm{ml}$ of acetonitrile was added to the precipitate, the sample was vortex-mixed followed by repeat centrifugation. The supernatants were combined, and the sample was evaporated to dryness using filtered compressed air in a $42^{\circ} \mathrm{C}$ water bath in a Zymark TurboVap ${ }^{\circledR}$ (Hopkinton, MA, USA) and stored at $-30^{\circ} \mathrm{C}$. On the day of analysis, the residue was re-suspended in $0.5 \mathrm{ml}$ HPLC water, incubated for $5 \mathrm{~min}$ in a $37^{\circ} \mathrm{C}$ water bath, and then clarified by centrifugation at 
$12000 \mathrm{~g}$ for $10 \mathrm{~min}$ at $20^{\circ} \mathrm{C}$. The resultant supernatant was filtered though a 1-ml syringe fitted with a GHP 13-mm Acrodisc, 2- $\mu \mathrm{m}$ pore size, with minispike outlet (Pall Gelman Laboratory, Ann Arbor, MI, USA). An aliquot of each sample was placed in $250-\mu l$ low volume glass inserts placed in 4-ml glass vials (Waters, Milford, MA, USA) and loaded into a 48-position carousel tray. The injection volume was $190 \mu \mathrm{l}$. The residuals of the reconstituted samples were stored at $-30{ }^{\circ} \mathrm{C}$ in the event that repeat injection was needed. Because the calibration standards were prepared in pre-chilled plasma on ice, the inclusion of THU (final concentration $1 \mu M$ ) during their preparation did not affect either the recovery or peak heights of the analytes or internal standard.

Blood samples from patients receiving $1000 \mathrm{mg} /$ $\mathrm{m}^{2}$ of $\mathrm{dFdC}$ were obtained using $10-\mathrm{ml}$ heparinized tubes containing $10 \mathrm{nmol}$ THU. The blood collection tubes were immediately placed on ice until centrifugation at $1000 \mathrm{~g}$ for $10 \mathrm{~min}$ at $4{ }^{\circ} \mathrm{C}$. Aliquots of plasma were stored at $-70{ }^{\circ} \mathrm{C}$ until analysis. Twenty microliters of $1 \mathrm{mM} F d C$ were added to $0.5-\mathrm{ml}$ aliquots of plasma, and the samples were then prepared as described above.

\section{High-performance liquid chromatography with photodiode array detection}

The Waters chromatographic system (Milford, MA, USA) was used consisting of a $600 \mathrm{E}$ Multisolvent Delivery System, a 717 plus Autosampler set at $4{ }^{\circ} \mathrm{C}$, a 996 Photodiode Array Detector and an in-line vacuum degasser. A Columbus ${ }^{\mathrm{TM}} \mathrm{C}_{18}$ column (5- $\mu \mathrm{m}$ particle size, $110 \AA$ pore size, $150 \times 4.6 \mathrm{~mm}$ ) was employed for the separations (Phenomenex, Torrance, CA, USA). The pre-column was a Waters $\mathrm{C}_{18}$ Nova-Pak Sentry guard column (4- $\mu \mathrm{m}$ particle size). A Micron Millennia computer (Nampa, ID, USA) was used to acquire data and perform the initial data analysis using Millenium 32 software version 3.2 (Waters).

HPLC solvent A was $50 \mathrm{~m} M$ sodium acetate $(\mathrm{pH}$ 5.0) with $2 \%(\mathrm{v} / \mathrm{v})$ methanol; solvent $\mathrm{B}$ was the same buffer with $10 \%(\mathrm{v} / \mathrm{v})$ methanol. Total flowrate was $1.5 \mathrm{ml} / \mathrm{min}$ and the column was at ambient temperature. The following program was run: $100 \%$ A for $17 \mathrm{~min}$, a linear gradient of $100 \%$ A to $100 \%$ B over $14 \mathrm{~min}, 100 \% \mathrm{~B}$ for $2 \mathrm{~min}$, and immediate return to $100 \% \mathrm{~A}$ and re-equilibration for $6 \mathrm{~min}$. $\mathrm{FdC}, \mathrm{dFdC}$ and $\mathrm{dFdU}$ were monitored at wavelengths of 282, 269 and $258 \mathrm{~nm}$, respectively.

\section{Calculations}

The ratios of the peak heights of $\mathrm{dFdC}$ or $\mathrm{dFdU}$ to $\mathrm{FdC}$ were calculated, which were then plotted versus the nominal total amount of $\mathrm{dFdC}$ or $\mathrm{dFdU}$ in the sample. The data were fitted using least squares linear regression with a weighting factor of $1 / y$, not including the origin, using SigmaPlot 2001 (SPSS, Chicago, IL, USA). Analyte concentrations were determined using the calibration lines thus generated.

\section{Recovery}

Plasma samples were prepared in triplicate containing six concentrations ranging from 0.5 to 100 $\mu M$ of $\mathrm{dFdC}$ and $\mathrm{dFdU}$; each sample contained a fixed concentration of FdC $(25 \mu M)$. Non-treated standards were samples in which the same concentration of the internal standard, $\mathrm{dFdC}$ or $\mathrm{dFdU}$ were prepared in water and not subjected to the precipitation procedure. The percent absolute recovery was defined as the (peak height of the precipitated plasma standard $\div$ peak height of the non-treated standard) $\times 100 \%$.

\section{Validation}

Concentrations of $\mathrm{dFdC}$ and $\mathrm{dFdU}$ were determined by three calibration curves run over a 3 -week period to compare the observed with the theoretical concentration. To determine within-run variation, triplicate samples at six different concentrations of $\mathrm{dFdC}$ and $\mathrm{dFdU}$ were prepared in human plasma, and the samples were injected on the same day. Between-run variation was determined by injecting triplicate samples prepared at three different concentrations on three separate occasions.

\section{Stability of samples}

The stability of the stock solutions of $\mathrm{dFdC}, \mathrm{dFdU}$ and $\mathrm{FdC}$ was tested by preparing three concentrations of the compounds in water, and analyzing an 
aliquot immediately and after storage at room temperature and at $-30{ }^{\circ} \mathrm{C}$.

\section{Analysis of patient plasma samples}

Patients were participating in an Institutional Review Board-approved Phase I clinical trial involving $\mathrm{dFdC}$ given as either a 1- or 2-h infusion followed by a 24-h infusion of FdU weekly for 3 of 4 weeks. All patients gave written, informed consent. A baseline plasma sample was obtained pre-therapy. To provide an estimate of steady-state gemcitabine plasma concentrations, samples were obtained at 30 , 40 and 50 min during the 1-h infusion, and at 90 and 105 min during the 2 -h infusion.

\section{Results}

\section{High-performance liquid chromatography}

$\mathrm{FdC}, \mathrm{dFdC}$ and $\mathrm{dFdU}$ were resolved from endogenous compounds with resulting retention times of $13.6 \pm 0.5,18.1 \pm 1.1$ and $29.0 \pm 0.6 \mathrm{~min}$, respectively. $\mathrm{dFdC}$ and $\mathrm{dFdU}$ were monitored at their optimal UV wavelengths, 269 and $258 \mathrm{~nm}$, respectively, under the experimental conditions as determined by spectral analysis using the photodiode array detector. Because an endogenous peak (that was not present when FdC stock solution was directly injected) eluted shortly after FdC, we compensated by increasing the amount of the internal standard from 25 to 40 $\mu M$, and monitoring the peak height at $282 \mathrm{~nm}$. These measures provided a greater peak height for FdC and allowed baseline resolution between FdC and the adjacent endogenous peak (Fig. 2). THU is not detectable under the conditions used.

\section{Recovery}

Absolute recovery of $\mathrm{FdC}, \mathrm{dFdC}$ and $\mathrm{dFdU}$ from plasma was compared to non-extracted samples prepared in water under identical concentrations. In preliminary studies, it was determined that the recovery was about $10 \%$ greater when the samples were filtered though a GHP $0.2-\mu \mathrm{m}$ syringe filter compared to the use of a PVDF filter. Application of a second acetonitrile precipitation improved the absolute recoveries by about $17 \%$ over that achieved with a single precipitation with $1 \mathrm{ml}$ acetonitrile; recovery with two sequential $1-\mathrm{ml}$ precipitations was also greater than a single precipitation with $2 \mathrm{ml}$ acetonitrile (data not shown). With the sample preparation described herein, the overall recovery of all three analytes from $0.5 \mathrm{ml}$ plasma was $\geq 70 \%$ for $\mathrm{dFdC}, \geq 68 \%$ for $\mathrm{FdC}$, and $\geq 82 \%$ for $\mathrm{dFdU}$ (Table 1).

\section{Accuracy and precision}

Data from three calibration curves prepared with six standard concentrations of $\mathrm{dFdC}$ and $\mathrm{dFdU}$ with a fixed $\mathrm{FdC}$ concentration that were examined over a 3 -week period are shown in Table 2. The percent coefficients of variation (\% CV) for $\mathrm{dFdC}$ were below $3 \%$ at concentrations $\geq 5 \mu M$, and were below $10.2 \%$ for 1 and $0.5 \mu M$. There was greater variability with dFdU: the \%CV was $22.2 \%$ with 0.5 $\mu M$, but was below $7 \%$ for higher concentrations with the exception of $5 \mu M(\% \mathrm{CV} 11.5 \%)$. The average $r^{2}$ values for the three calibration curves were above 0.998 for both $\mathrm{dFdC}$ and $\mathrm{dFdU}$.

Within-run variation was assessed using six concentrations of $\mathrm{dFdC}$ and $\mathrm{dFdU}$ with fixed concentrations of $\mathrm{FdC}(25 \mu M)$ and THU $(1 \mu M)$ prepared in triplicate. The results of within-run variation were determined by comparing the peak heights for $\mathrm{dFdC}$, $\mathrm{dFdU}$ and FdC for these nine separate samples injected into the HPLC system on the same day. The coefficients of variation ranged from 1.1 to $6.0 \%$ for $\mathrm{dFdC}$, and were $<4.3 \%$ for $\mathrm{dFdU}$ and $\mathrm{FdC}$ (Table 3 ). Assessment of between-run variability was carried out subsequently using concentrations of $\mathrm{dFdU}$ and $\mathrm{dFdC}$ that would encompass the expected plasma concentrations taken from patients during the 1- to 2-h $\mathrm{dFdC}$ infusion. The coefficients of variation were $\leq 5.1 \%$ for three compounds (Table 4 ).

\section{Linearity}

The assay was linear between 0.5 and $150 \mu M$ $(0.13-39.4 \mu \mathrm{g} / \mathrm{ml})$ for $\mathrm{dFdC}$ and 1 to $227 \mu M$ $(0.26-60.0 \mu \mathrm{g} / \mathrm{ml})$ for $\mathrm{dFdU}$. 


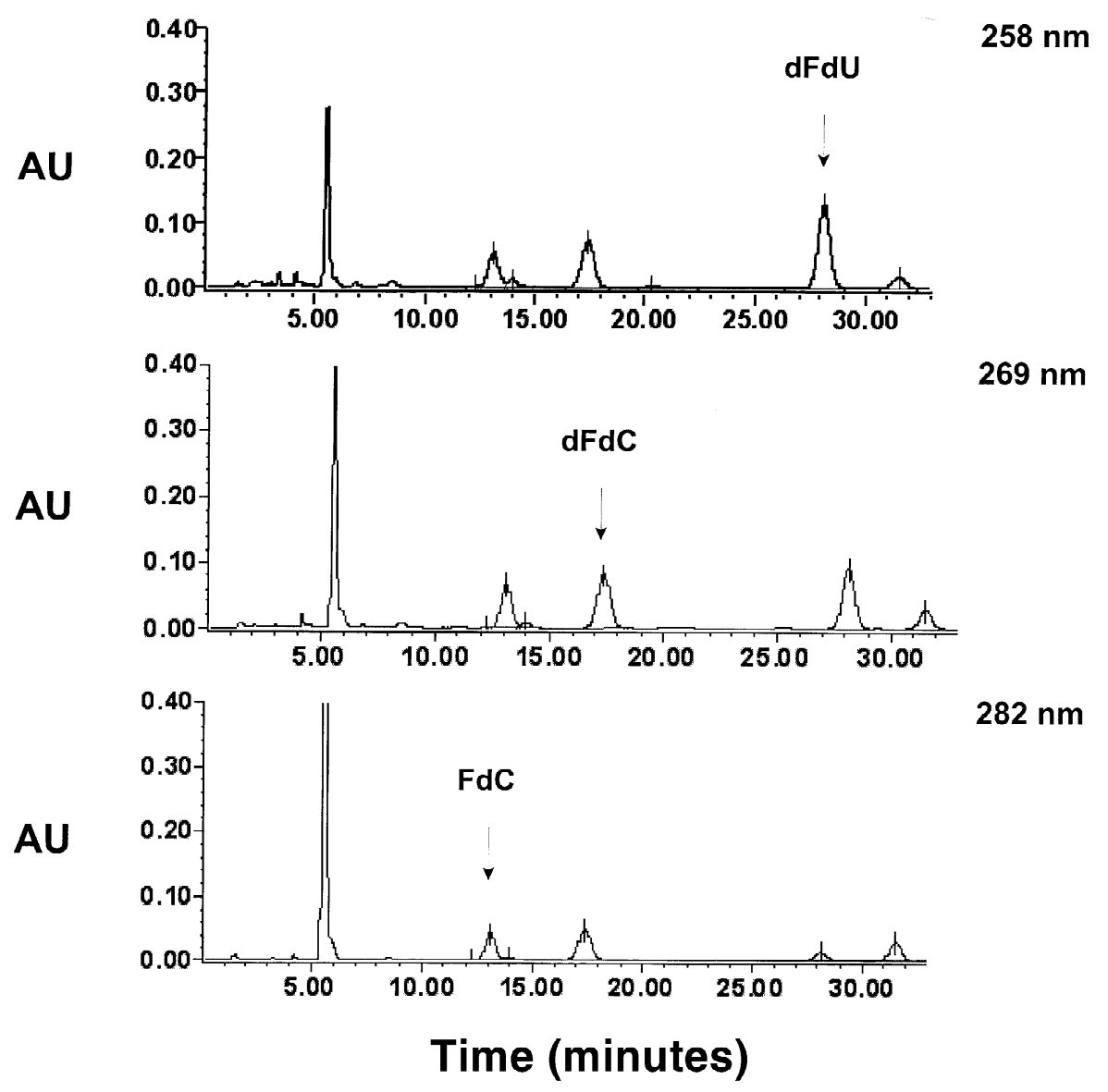

Fig. 2. Chromatography and UV detection of $\mathrm{dFdC}$ and $\mathrm{dFdU}$ in the plasma of a patient $40 \mathrm{~min}$ after the start of a 1-h infusion of 1000 $\mathrm{mg} / \mathrm{m}^{2}$ of $\mathrm{dFdC}$. Identified peaks include the internal standard, $\mathrm{dFdC}$ and $\mathrm{dFdU}$. The calculated plasma concentrations of $\mathrm{dFdC}$ and $\mathrm{dFdU}$ were 23.7 and $59.2 \mu M$, respectively.

Table 1

Absolute recovery of internal and calibration standards

\begin{tabular}{|c|c|c|c|c|c|c|c|}
\hline Analyte & & $0.5 \mu M$ & $1 \mu M$ & $5 \mu M$ & $10 \mu M$ & $50 \mu M$ & $150 \mu M$ \\
\hline \multirow[t]{3}{*}{$\mathrm{dFdC}$} & Mean & 75.8 & 78.8 & 80.2 & 86.3 & 70.0 & 78.5 \\
\hline & $\mathrm{SD}$ & 1.2 & 0.9 & 1.2 & 3.5 & 2.6 & 4.7 \\
\hline & $\% \mathrm{CV}$ & 1.6 & 1.1 & 1.5 & 4.1 & 3.8 & 6.0 \\
\hline \multirow[t]{3}{*}{$\mathrm{dFdU}$} & Mean & 95.2 & 86.4 & 87.4 & 81.8 & 87.5 & 101.4 \\
\hline & SD & 2.6 & 1.0 & 1.7 & 3.5 & 0.8 & 2.2 \\
\hline & $\% \mathrm{CV}$ & 2.8 & 1.2 & 2.0 & 4.3 & 0.9 & 2.2 \\
\hline \multirow[t]{3}{*}{$\mathrm{FdC}$} & Mean & 68.3 & 76.2 & 67.9 & 83.4 & 68.0 & 75.8 \\
\hline & SD & 1.8 & 1.5 & 1.5 & 3.5 & 2.1 & 0.9 \\
\hline & $\% \mathrm{CV}$ & 2.7 & 2.0 & 2.2 & 4.2 & 3.1 & 1.2 \\
\hline
\end{tabular}

Triplicate samples of internal standard (fixed concentration of $25 \mu M$ ) and calibration standards were prepared in both plasma and water. The plasma was subjected to the sample preparation described in Section 2, whereas aliquots of the standards prepared in water were directly injected into the HPLC without further processing. 
Table 2

Gemcitabine $(\mathrm{dFdC})$ and $2^{\prime}, 2^{\prime}$-difluorodeoxyuridine (dFdU) calibration standards in human plasma

\begin{tabular}{|c|c|c|c|c|}
\hline $\begin{array}{l}\text { Concentration } \\
(\mu M)\end{array}$ & $\begin{array}{l}\text { Measured dFdC }(\mu M) \\
(\text { mean } \pm \mathrm{SD})\end{array}$ & $\begin{array}{l}\mathrm{dFdC} \\
\% \mathrm{CV}\end{array}$ & $\begin{array}{l}\text { Measured dFdU }(\mu M) \\
(\text { mean } \pm \mathrm{SD})\end{array}$ & $\begin{array}{l}\mathrm{dFdU} \\
\% \mathrm{CV}\end{array}$ \\
\hline 150 & $152.1 \pm 3.0$ & 2.0 & $152.4 \pm 3.4$ & 2.2 \\
\hline 50 & $48.7 \pm 1.2$ & 2.5 & $48.2 \pm 1.5$ & 3.1 \\
\hline 10 & $9.4 \pm 0.3$ & 2.7 & $9.8 \pm 0.7$ & 6.7 \\
\hline 5 & $4.8 \pm 0.10$ & 2.0 & $4.7 \pm 0.5$ & 11.5 \\
\hline 1 & $1.0 \pm 0.1$ & 10.2 & $1.1 \pm 0.0$ & 1.6 \\
\hline 0.5 & $0.53 \pm 0.05$ & 8.8 & $0.52 \pm 0.11$ & 22.2 \\
\hline Calibration curve parameters & $\mathrm{dFdC}$ & & $\mathrm{dFdU}$ & \\
\hline$r^{2}$ & $0.9989 \pm 0.0009$ & & $0.9985 \pm 0.0014$ & \\
\hline$X$-coefficient & $0.075 \pm 0.005$ & & $0.067 \pm 0.016$ & \\
\hline$Y$-intercept & $-0.0038 \pm 0.0095$ & & $0.0262 \pm 0.0360$ & \\
\hline
\end{tabular}

The data are from three calibration curves in human plasma done over a 3-week period. The internal standard concentration was $40 \mu M$.

Table 3

Within-run precision for gemcitabine $(\mathrm{dFdC})$ and $2^{\prime}, 2^{\prime}$-difluorodeoxyuridine $(\mathrm{dFdU})$ in human plasma

\begin{tabular}{|c|c|c|c|c|c|c|c|c|c|}
\hline \multirow{2}{*}{$\begin{array}{l}\text { Concentration } \\
(\mu M)\end{array}$} & \multicolumn{3}{|l|}{$\mathrm{dFdC}$} & \multicolumn{3}{|l|}{$\mathrm{dFdU}$} & \multicolumn{3}{|l|}{$25 \mu M \mathrm{FdC}$} \\
\hline & Peak height & SD & $\% \mathrm{CV}$ & Peak height & SD & $\% \mathrm{CV}$ & Peak height & SD & $\% \mathrm{CV}$ \\
\hline 05 & 1917 & 73 & 38 & 2232 & 62 & 28 & 76717 & 627 & 08 \\
\hline 1 & 4614 & 274 & 59 & 5413 & 119 & 22 & 79946 & 1571 & 20 \\
\hline 5 & 22625 & 334 & 15 & 21226 & 422 & 20 & 76761 & 1954 & 26 \\
\hline 10 & 53242 & 2186 & 41 & 40011 & 1732 & 43 & 77222 & 3214 & 42 \\
\hline 50 & 223332 & 3488 & 16 & 229301 & 2037 & 09 & 73603 & 5146 & 70 \\
\hline 150 & 896568 & 9901 & 11 & 600932 & 7148 & 12 & 68415 & 831 & 12 \\
\hline
\end{tabular}

The data are from samples prepared in triplicate and injected during the same HPLC run.

\section{Stability}

It has been reported that both gemcitabine and $\mathrm{dFdU}$ are stable for at least 21 months at $-70{ }^{\circ} \mathrm{C}$ in THU-treated human plasma, and that both analytes were unaffected by three freeze-thaw cycles [8]. Therefore, we did not repeat this analysis. In the current study, stock solutions of $1 \mathrm{~m} M \mathrm{FdC}, 1 \mathrm{~m} M$, 100 and $10 \mu M \mathrm{dFdC}$, and $7.57 \mathrm{mM}, 378.5$ and $37.85 \mu M \mathrm{dFdU}$ were stable at $-30{ }^{\circ} \mathrm{C}$ for at least 1 month, and at both $4{ }^{\circ} \mathrm{C}$ and room temperature for at least 1 week (data not shown).

\section{Testing of patient plasma samples}

Plasma $\mathrm{dFdC}$ and $\mathrm{dFdU}$ concentrations were determined as part of a Phase I trial of weekly $\mathrm{dFdC}$ followed by infusional FdU. The plasma concentrations for six patients each receiving $1000 \mathrm{mg} / \mathrm{m}^{2}$ $\mathrm{dFdC}$ as either a 1- or 2-h infusion are shown in Fig.

Table 4

Between-run precision for gemcitabine $(\mathrm{dFdC})$ and $2^{\prime}, 2^{\prime}$-difluorodeoxyuridine (dFdU) in human plasma

\begin{tabular}{|c|c|c|c|c|c|c|c|c|c|c|}
\hline \multicolumn{2}{|c|}{ Concentration $(\mu M)$} & \multicolumn{3}{|l|}{$\mathrm{dFdC}$} & \multicolumn{3}{|l|}{$\mathrm{dFdU}$} & \multicolumn{3}{|l|}{$40 \mu M \mathrm{FdC}$} \\
\hline $\mathrm{dFdC}$ & $\mathrm{dFdU}$ & Peak height & SD & $\% \mathrm{CV}$ & Peak height & SD & $\% \mathrm{CV}$ & Peak height & $\mathrm{SD}$ & $\% \mathrm{CV}$ \\
\hline 5 & 15 & 25449 & 389 & 15 & 74850 & 1755 & 24 & 107342 & 3007 & 24 \\
\hline 25 & 95 & 125054 & 962 & 08 & 428440 & 21737 & 51 & 108677 & 3053 & 28 \\
\hline 100 & 227 & 524059 & 10345 & 20 & 1009497 & 39371 & 39 & 112268 & 1977 & 18 \\
\hline
\end{tabular}

The data are from samples prepared in human plasma in triplicate and injected on three different days. 


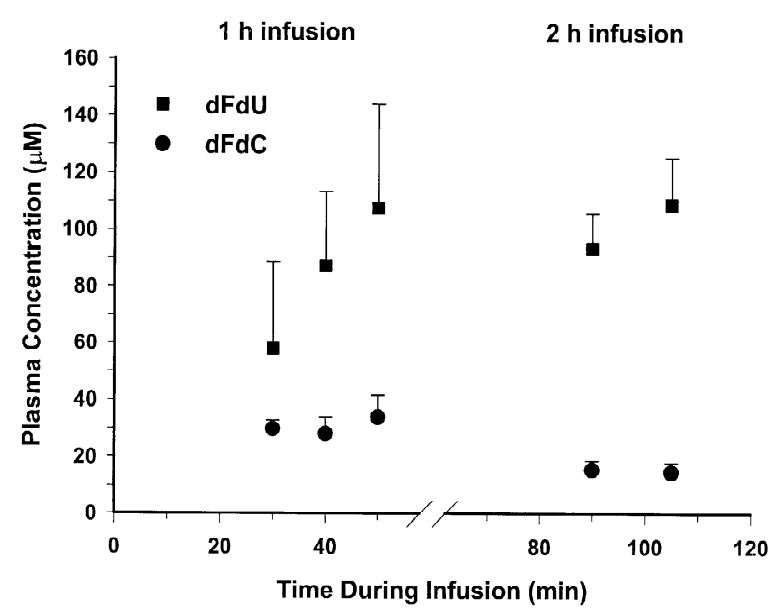

Fig. 3. Plasma concentrations of $\mathrm{dFdC}$ and $\mathrm{dFdU}$ in patients receiving $1000 \mathrm{mg} / \mathrm{m}^{2}$ gemcitabine. The data, shown as the mean $\pm \mathrm{SD}$, are from six patients who each received either a 1-h or 2-h infusion.

3. There were no interfering endogenous peaks in the pre-therapy samples under the conditions used. In all patients, $\mathrm{dFdC}$ and $\mathrm{dFdU}$ were detected at the planned sampling times. The $\mathrm{dFdC}$ levels were similar at 30, 40 and $50 \mathrm{~min}$ in patients receiving a 1-h infusion, and at 90 and $105 \mathrm{~min}$ in those receiving a 2-h infusion, suggesting the drug was at or near steady-state. The average plasma levels for all time points for the 1-h infusion, $30.7 \mu M$, was about twofold higher than that observed with the 2-h infusion, 15.2 $\mu M$. In contrast, the dFdU levels appeared to be increasing throughout the infusion, and were on average 3.2- and 7.6-fold higher than the corresponding $\mathrm{dFdC}$ levels at the 50- and 105min sampling times after the start of a 1- and 2-h infusion, respectively. This observation is consistent with a longer half-life for $\mathrm{dFdU}$, which is cleared by renal excretion, as opposed to the predominantly metabolic clearance of $\mathrm{dFdC}$.

\section{Discussion}

In the process of developing the current method, we evaluated several methods for sample preparation, including solid-phase extraction using different types of cartridges (phenylboronate, $\mathrm{C}_{18}$ ), and liquid-liquid extraction using either methanol, ethyl acetate, or acetonitrile. We found that liquid-liquid extraction with two sequential acetonitrile applications yielded the best recovery.

Several studies have been published that describe analysis of $\mathrm{dFdC}$ and $\mathrm{dFdU}$ in plasma samples obtained from cancer patients receiving gemcitabine [6-10]. However, only a few employed an internal standard and provided sufficient information to ensure method reproducibility [6,9]. The first validated assay reported from researchers at Lilly Research Laboratories used normal-phase HPLC with an Alltech ${ }^{\mathrm{TM}}$ amino column [6]. The procedure required sequential liquid-liquid extraction using both isopropanol and ethyl acetate followed by concentration to dryness; the reconstituted residue was then filtered though an ultra-free MC filter to remove insoluble material. The mobile phase represented an aqueous mixture containing five different solvents.

An additional published method used acetonitrile precipitation for sample preparation, and an isocratic mobile phase of $15 \mathrm{~m} M$ ammonium acetate, $\mathrm{pH} 5.0$, and acetonitrile $(97.5: 2.5, \mathrm{v} / \mathrm{v})$ for $47 \mathrm{~min}$ followed by a linear increase to $15 \mathrm{~m} M$ ammonium acetate, pH 5.0, and acetonitrile (95:5, v/v) over 5 min [9]. The latter solvent was run isocratically for $10 \mathrm{~min}$ followed by a linear return over $5 \mathrm{~min}$ to initial conditions. The column was allowed to equilibrate for $10 \mathrm{~min}$ prior to the next injection, for an overall cycle time of $77 \mathrm{~min}$ to resolve $\mathrm{dFdC}, \mathrm{dFdU}$ and the internal standard, $2^{\prime}, 2^{\prime}$-difluorodeoxythymidine.

The current method employs reversed-phase HPLC that offers a shorter cycling time (39 min), partly due to the selection of the internal standard $\mathrm{FdC}$, which elutes sooner than $\mathrm{dFdC}$ and has similar recovery. This method has proven useful in the analysis of samples from patients receiving $\mathrm{dFdC}$ given as a 1- or 2-h infusion weekly for 3 of 4 weeks. By using a smaller volume of plasma (0.1$0.2 \mathrm{ml}$ ), the methodology described herein can also be employed in the analysis of samples obtained during a 30-min infusion of $\mathrm{dFdC}$.

\section{References}

[1] W. Plunkett, V. Gandhi, S. Chubb, B. Nowak, V. Heinemann, S. Mineishi, A. Sen, L.W. Hertel, G.B. Grindey, Nucleosides Nucleotides 8 (1989) 775. 
[2] V. Heinemann, Y.Z. Xu, S. Chubb, A. Sen, L.W. Hertel, G.B. Grindey, W. Plunkett, Mol. Pharmacol. 38 (1990) 567.

[3] S. Noble, K.L. Goa, Drugs 54 (1997) 447.

[4] Q.-F. Ren, V. Kao, J.L. Grem, Clin. Cancer Res. 4 (1998) 2811.

[5] R.B. Stoller, C.E. Myers, B.A. Chabner, Biochem. Pharmacol. 27 (1978) 53.

[6] K.B. Freeman, S. Anliker, M. Hamilton, D. Osborne, P.H. Dhahir, R. Nelson, S.R.B. Allerheiligen, J. Chromatogr. B 665 (1995) 171.

[7] J.L. Abbruzzese, R. Grunewald, E.A. Weeks, D. Gravel, T. Adams, B. Nowak, S. Mineishi, P. Tarassoff, W. Satterlee, M.N. Raber, W. Plunkett, J. Clin. Oncol. 9 (1991) 491.
[8] J.R. Kroep, G. Giaccone, D.A. Voorn, E.F. Smit, J.H. Beijnen, H. Rosing, C.J.A. van Moorsel, C.J. van Groeningen, P.E. Postmus, H.M. Pinedo, G.F. Peters, J. Clin. Oncol. 17 (1999) 2190.

[9] A.P. Venook, M.J. Egorin, G.L. Rosner, D. Hollis, S. Mani, M. Hawkins, J. Byrd, R. Hohl, D. Budman, N.J. Meropol, M.J. Ratain, J. Clin. Oncol. 18 (2000) 2780.

[10] H.T. Edzes, G.J. Peters, P. Noordhuis, J.B. Vermorken, Anal. Biochem. 214 (1993) 25.

Post-print standardized by MSL Academic Endeavors, the imprint of the Michael Schwartz Library at Cleveland State University, 2017. 